\title{
When Knowledge Wins: Transcending the Sense and Nonsense of Academic Rankings
}

\author{
NANCY J. ADLER \\ McGill University
}

ANNE-WIL HARZING

University of Melbourne

"Not everything that can be counted counts, and not everything that counts can be counted."-Albert Einstein

Has university scholarship gone astray? Do our academic assessment systems reward scholarship that addresses the questions that matter most to society? Using international business as an example, we highlight the problematic nature of academic ranking systems and question if such assessments are drawing scholarship away from its fundamental purpose. We call for an immediate examination of existing ranking systems, not only as a legitimate scholarly question vis-à-vis performance - a conceptual lens with deep roots in management research-but also because the very health and vibrancy of the field are at stake. Indeed, in light of the data presented here, which suggest that current systems are dysfunctional and potentially cause more harm than good, a temporary moratorium on rankings may be appropriate until more valid and reliable ways to assess scholarly contributions can be developed. The worldwide community of scholars, along with the global network of institutions interacting with and supporting management scholarship (such as the Academy of Management, AACSB, and Thomson Reuters Scientific) are invited to innovate and design more reliable and valid ways to assess scholarly contributions that truly promote the advancement of relevant 21st century knowledge, and likewise recognize those individuals and institutions that best fulfill the university's fundamental purpose.

"Measurement of scientific productivity is difficult. The measures used ... are crude. But these measures are now so universally adopted that they determine most things that matter [to scholars]: tenure or unemployment, a postdoctoral grant or none, success or failure. As a result, scientists have been forced to downgrade their primary aim from making discoveries to publishing as many papers as possible-and trying to work them into high impact-factor journals. Consequently, scientific behaviour has become distorted and the utility, quality, and

objectivity of articles have deteriorated. Changes ... are urgently needed ..."

-Peter Lawrence, Cambridge University (2008: 1)
Truly great universities are one of society's greatest assets (Garten, 2006). The world's first university, Nalanda, founded in 427 C.E. (almost a millennium before the most prominent universities of Europe and the Americas) near the Nepalese border in what is now India, boasted over 10,000 students and 2,000 professors. Former Dean of Yale's School of Management Jeffrey Garten (2006), in supporting Asia's 2lst century revival of Nalanda, raised a fundamental question: Do societies understand that real power comes from great ideas and from the people who generate them? Do today's universities, operating more than sixteen centuries

There is no way that this paper would have been born without the thoughtful and consistent support from the wide range of people who care passionately about issues of academic process, and who took the time to read and reread the manuscript as it went through its 150 iterations prior to being published. We 
after the founding of Nalanda, remember that their primary role is to support scholarship that addresses the complex questions that matter most to society?

Many leaders both inside and outside academia fear that universities today are no longer fulfilling their fundamental mission; they fear that university scholarship has gone astray. The Financial Times, for example, recently asked "why business ignores business schools" and concluded that business views business school research as irrelevant, pointedly highlighting the fact that "[c]hief executives ... pay little attention to what business schools do or say" (Skapinker, 2008; see also Pfeffer \& Fong, 2002). Writing in the Academy of Management Journal, one of academia's most prestigious journals, Professor McGrath (2007: 1372) noted that "Most of what we publish isn't even cited by other academics."

Underscoring the importance of returning to a broader and more relevant appreciation of university scholorship, the prestigious 18,000-member Academy of Management chose "The Questions We Ask" as its 2008 conference theme. The highly regarded Academy of International Business similarly fostered a prominent search to identify the most important 2lst century question(s) (Adler, 2008a, 2008b; Buckley, 2002; Buckley \& Lessard, 2005; Butler, 2006; and Peng, 2004, among others). London Business School convened a conference in 2007 on "Conducting Research with Relevance to Practice," honoring Sumantra Ghoshal (see Ghoshal, 2005; Pfeffer, 2005; Donaldson, 2005), a leading international business scholar who com-

would especially like to thank James Bailey, one of $A M L E^{\prime}$ s founding editors, who first saw the potential of the paper to help shape the field. Similarly, we would like to profusely thank Rich Klimoski, who defines what it means to give generative feedback (as opposed to the much more common evaluative feedback). With the addition of an institutional perspective, Rich's suggestions took the paper far beyond its initial, more circumscribed appreciation of the dynamics at play. We thank Eleanor Westney, who guided us in our growing appreciation of how institutional theory, and more important, institutional entrepreneurship could explain the dynamics within our field. We also owe a huge debt of gratitude to Troy Anderson for his multiple readings and detailed suggestions on what had to change to make the paper work. In addition, we would like to thank the many people who read various iterations of the paper and generously offered their perspective, suggestions, and encouragement, including Ariane Berthoin Antal, Art Bedeian, Howard Browman, Michelle Buck, Christina Cregan, Lorraine Eden, Axele Giroud, Carol Kulik, Yadong Luo, Steve Maguire, David Merrett, Niels Noorderhaven, Ron van der Wal, Jim Walsh, Sri Zaheer, and Tatiana Zalan. We are grateful to Ben Arbaugh, Myrtle Bell, and Jonathan Doh, the new AMLE editorial team, for their expert choices in how best to present the set of ideas to the public. mitted his career to "maintaining academic respectability by combining rigor with relevance" (Rynes, 2007b). Following the conference, the Academy of Management Journal (AMJ) convened an Editor's Forum on "Research with Relevance to Practice" (Rynes, 2007b), highlighting some of the best thinking to date on how to recombine important, interesting, integrative, and globally relevant research with rigor (see Gulati, 2007; McGahan, 2007; Tushman \& O'Reilly, 2007; and Vermeulen, 2007).

In this article, we question whether the academic assessment systems currently used to rank scholars, universities, and journals undermine, rather than foster and reward, scholarship that matters. We invite scholars from around the world, along with the global network of institutions interacting with scholars and supporting management scholarship, to create new systems that would support the advancement of knowledge by encouraging the types of contributions that matter most to the broader society.

\section{THE PROLIFERATION OF ACADEMIC RANKING SYSTEMS}

\author{
"The result is an 'audit society' in which \\ each indicator is invested with a specious \\ accuracy and becomes an end in itself." \\ -Peter Lawrence (2003: 259)
}

In stark contrast to the goal of asking and researching questions that matter, the past decades have witnessed a growing competition among individual scholars, universities, and journals to achieve high rankings (see, e.g., MacDonald \& Kam, 2007; Segalla, 2008a). According to Cambridge University scholar and journal editor Peter Lawrence (2003: 259), "[s]cientists are increasingly desperate to publish in a few top journals and are wasting time and energy manipulating their manuscripts and courting editors. As a result, the objective presentation of work, the accessibility of articles, and the quality of research itself are being compromised."

All professions (and organizations), of course, use metrics and benchmarks to assess their progress. The very concept of measurement became central to the ascendency of scientific methods during the Enlightenment, and thus has been viewed as a primary contributor to human knowledge for centuries. Given its primacy, it is incumbent on all professions to regularly reconsider whether their key metrics-their key performance indicators-are accomplishing what they are intended to accomplish. Whereas management is no exception, no field is potentially better equipped 
than our own to set an example of what effective, thoughtful, and encompassing performance indicators could be. Management must therefore reconsider the metrics it most pervasively uses to make certain that it has not created a web of "unintended consequences" (Merton, 1936: 897) by having fallen into the "folly", as labeled by former Academy of Management President Steven Kerr (1975: 769), "of rewarding $A$ [publications in a norrow set of top-listed journals] while hoping for B [scholarship that addresses the questions that matter most to society]". Our profession needs to guard against turning rankings into, as James March described such metrics in his 1996 (p. 286) Administrative Science Quarterly article, "magic numbers" invested with a sacred, but false, aura of truth.

While the most publicized rankings are media rankings of undergraduate and MBA programs (see, e.g., Gioia \& Corley, 2002; Morgeson \& Nahrgang, 2008; Zemsky, 2008), the most aspired-to rankings claim to measure what is labeled as research productivity, with the definition of productivity often reduced to simply counting publications in high impact-factor journals along with citations in the limited set of journals that such systems recognize (see Rynes, 2007a). Rather than genuinely fostering relevant knowledge, the emphasis on ronking seems to be driven by a desire to identify winners and losers in a game of academic prestige. The stated reasons for creating and using such academic ranking systems usually include (a) "fairness" in universities' hiring, promotion, and tenure decisions, and (b) accountability and valuefor-research-dollars in the grant-awarding processes of governments and other providers of research funds (Murphy, 1996).

Governments worldwide, all of which have mandates to foster society's best interest, have introduced formal rankings-based research assessment processes. Although the British Research Assessment Exercise is probably the oldest and best known of such systems, it is by no means unique. These national research evaluation systems reinforce universities' proclivity to systematically rank journals, scholars, and academic institutions.

Some disciplines embraced academic ranking much earlier and more extensively than did others. Within business, rankings first became prominent in accounting, economics, and finance. In a comprehensive evaluation going back to 1956, Macri and Sinha (2006) reviewed nearly 50 ranking studies in economics alone. In just the past year, a single journal (Review of Quantitative Finance and Accounting) published no less than four articles on rankings in finance and accounting. Fol- lowing their lead, other management disciplines created their own systems and studies.

Using international business (IB) as an example, we illustrate how rankings of both scholars and universities are subject to a range of arbitrary decisions, including those related to choice of publication outlet, choice of time period, weighting of data, and aggregation of individuals to an institutional level. In reviewing the arbitrary nature of these commonly used but questionable ranking practices, we present the problematic nature of journal rankings and citation analyses. We express reservations about the validity and reliability of current academic rankings, and question whether such systems fundamentally undermine the very purpose of universities and university scholarship. In reviewing the currently enacted system, we invite the field to identify alternatives to the present situation that will result in both the creation of more research that is of greater use to society, and the development of more accurate and fair ways to recognize researchers and their contributions to research that matters.

\section{RANKING SYSTEMS: THE ARBITRARY NATURE OF DECISION CRITERIA}

\author{
"What has rank to do with the process of \\ creative discovery in science? Very little. \\ What has rank to do with the politics of \\ science and the allocation of credit for \\ discoveries? Almost everything." \\ -Peter Lawrence (2002: 835)
}

Once the decision is made to rank individual scholors or universities, the most important decision is the set of criteria on which the rankings will be based. Should individuals and universities be ranked according to productivity (based on such measures as the total number of publications or publications in "prestigious" journals), impact (based on such metrics as the number of people citing the author's work or citing work in the journal in which on author's article is published), and/or some surrogate for quality (such as an expert reading of the article, publication in a journal that has a very low acceptance rate or that is led by a highly respected editorial board, selection as an "editor's choice," best publication of the year, or other quality-based recognition)?

Published assessments vary substantially in terms of the publication outlets and weightings on which they are based. Each choice leads to different outcomes, and thus the appearance-if not the reality-of arbitrariness. In international business, for 
example, where most IB rankings have been based on publication counts (as opposed to citation counts), usually in a subset of IB journals, no IB ranking currently enjoys a consensus regarding its superiority over competing approaches. Whereas each system adds value within its own circumscribed domain, none constitutes an adequate basis for the important decisions universities make concerning hiring, promotion, tenure, and grant making, or for the ranking of individuals or institutions.

\section{Which Publications to Include: The Need to Become More Global and Comprehensive}

\author{
"Many ... articles would be better \\ appreciated, published more quickly, and \\ perhaps have more impact if they were \\ published in specialised journals. \\ However, because [specialized] ... journals \\ tend to have lower citation impact, or are \\ less well known, they are avoided by \\ young researchers trying to build on \\ impressive promotion file. This is an \\ understandable strategy, but one that \\ ultimately slows the diffusion of ideas into \\ the research literature and stifles \\ academic dialogue." \\ —Michael Segalla (2008a: 126)
}

\section{Why Only Journal Articles?}

To date, most rankings privilege articles in select journals (such as those appearing on the Financial Times list of top-40 journals in economics and business [FT40] and the University of Texas at Dallas list of the top-24 journals in business [UTD]). There are, however, convincing arguments for incorporating a more encompassing set of publications, including books, book chapters, conference proceedings, and a much wider range of journals.

Books, for example, often offer a depth of analysis that is impossible in a limited-length article. Moreover, the impact of books is often greater than that of articles, even those published in the best journals. Based on their analysis of emerging research themes, Griffith, Cavusgil, and Xu (2008: 1233) acknowledged that "some of the most important contributions to the international business literature have been advanced through non-journal outlets." In their Delphi study, Griffith et al. (2008) asked prolific authors to nominate recent influential books: Nine of the nominated books received more than 100 citations in Google Scholor, with some receiving considerably more citations than influential articles. Similarly recognizing the importance of books, a re- cent study of citations in the top three IB journals revealed that scholarly books made up more than $40 \%$ of the most cited works. New cross-disciplinary concepts that address the multifaceted aspects of most societal issues rarely find a home in traditional disciplinary journals. Such contributions are most likely to be conveyed in the form of books, book chapters, or multidisciplinary journals.

Conference proceedings are more likely to communicate research in a timely fashion than are journals. Today, the growth in open-source publishing is beginning to challenge all traditional, limited-access, slow-turnaround (and often highly prestigious) journals (Cohen, 2008). The field of computer science provides a compelling, but troubling, example. Conference proceedings constitute the most important publication outlet in computer science, due primarily to the ropid advonces in the field. The world's most cited computer scientist, Hector Garcia-Molina (see http://www.cs.ucla.edu/ palsberg/h-number.html) has gathered nearly 30,000 citations in Google Scholar, with most of his papers having been published and cited in conference proceedings. In the Science Citation Index, however, Garcia-Molina only receives slightly more than 250 citations, as Thomson Reuters ISI fails to appreciate the importance of timeliness, and chooses not to recognize citations in conference proceedings. As the rate of societal change quickens, cycle times in academic publishing, which have lagged behind those in industry and technology, become crucial. In a world of instant communication in which 70 million blogs already exist and 40,000 new blogs come on line each day-the majority of which are not in English (Lanchester, 2008) - academia cannot continue to rely on a venerated journal-publishing system that considers publication delays of up to 2 years to be both acceptable and normal.

In a world of instant communication in which 70 million blogs already exist and 40,000 new blogs come on line each day-the majority of which are not in English (Lanchester, 2008)-academia cannot continue to rely on a venerated journal-publishing system that considers publication delays of up to 2 years to be both acceptable and normal.

Taking a leadership position, Harvard announced in 2008 that it plans to begin publishing all research articles free on-line, so that the ideas will be immediately available to the wider public (Cohen, 2008). Rather than waiting to be published in 
TABLE 1

Journal Abbreviations

Academy of Management Journal

Academy of Management Learning and Education

Academy of Management Review

Administrative Science Quarterly

Asia Pacific Journal of Management

International Business Review

International Journal of HRM

International Marketing Review

Journal of Applied Psychology

Journal of International Business Studies

Journal of International Marketing

Journal of World Business

Management International Review

Strategic Management Journal

often highly expensive, limited-circulation journals, web-based open-access publishing guarantees that new articles are available in a timely fashion to a broad audience. As Carroll (2008) indicates, the discussion about copyright is not just technical, "it reflects a difference of opinion about the value of public access to scholarly thought and research." Will the same authors who choose webbased publishing also continue to publish in peerreviewed journals? The answer is not clear. What is clear is that the goal of fostering knowledge by making scholarly research accessible to as many people as possible, free of cost, could well trump more arcane publishing processes, and simultaneously, the ranking systems that have relied on restricted publishing in "elite" journals. No ranking system that chooses to ignore work published on the web will remain meaningful. No scholar who chooses to limit his or her intellectual base to work that, while published in top-ranked journals, is already 2-3 years out of date, can remain relevant.

\section{Why English Only?}

If rankings are to be relevant to 21st century scholarship, they need to expand beyond work published in English. In management, the five journals consistently identified as top (AMJ, AMR, ASQ, JAP, and SMJ; see Table 1 for abbreviations) are all published in English and are dominated by the U.S. research community and its particular definition of scientific rigor (Singh, Haddad, \& Chow, 2007). Singh et al. (2007: 320) suggest that editors and editorial board members of these journals "tend to emphasize technical thoroughness and refinement over the advancement of less technically developed but potentially more fundamental ideas (Swanson, 2004)." Similarly, the Thomson Re- uters ISI citation indices are derived almost entirely from journals published in English. Making this bias explicit, Thomson Reuters Scientific states that "English is the universal language of science at this time in history.... Thomson Scientific [therefore] focuses on journals that publish full text in English or at the very least, their bibliographic information in English" (Testa, nd).

By contrast, Google Scholar, rarely used by those constructing rankings, includes on-line scholarship from around the world, irrespective of language of publication. Publishing in accounting illustrates the dramatically different results achieved using Google Scholar versus Thomson Reuters ISI as a data source. French accounting scholar Gérard Charreaux accumulated some 30 citations in ISI-listed journals over his lifetime, while Google Scholar credits him with over 1,000. The reason is both easy to understand and unacceptable: Most of Charreaux's citations occur in French journals that are not ISI listed. It would be extremely unfortunate if we were to conclude (based on ISI data) that Charreaux has had no impact on his field.

\section{Why Only These Particular Journals?}

Most rankings evaluate individuals and universities based on articles published in a subset of journals. Journals in the selected subset are generally labeled as being high-impact, core, A-list, or top, based on a combination of explicit and implicit criteria. Although currently widely accepted as being valid indicators of quality, the most commonly used lists of A-level journals neither claim to comprehensively include "the best of the best" nor do they inadvertently succeed in such a task. The journals included in the FT40 and the UTD lists, for example, are merely a sample of highquality journals; they do not even attempt to represent (let alone equitably and comprehensively include) all 13 (AACSB-defined) disciplines associated with business. While these lists include more journals from accounting and finance, they fail to list all top-quality journals within most business fields. Similar to other well-known lists, the FT40 does not reveal how the 40 journals on its list are selected; however, given that the FT40 includes both academic and practitioner journals, it is clear that top-quality scholarship is not its only criterion.

Like the broader field, a brief review of several IB studies illustrates the arbitrary nature of journal selection for academic rankings. Early studies either included only JIBS (Inkpen \& Beamish, 1994) or included JIBS and JWB along with up to seven 
additional top-ranked functional journals such as AMJ, Journal of Finance, and Journal of Marketing (Morrison \& Inkpen, 1991). More recent rankings have added two general IB journals, MIR (Kumar \& Kundu, 2004) and IBR (Chan, Fung, \& Lai, 2006), while dropping all journals that focus only on a single discipline (such as marketing or finance).

Whereas arguments can be made both for the inclusion of broader multidisciplinary journals and for more narrowly focused disciplinary journals, the two alternatives produce significantly different rankings, and implicitly convey different appreciations of what scholarship is most valuable. Xu, Yalcinkaya, and Seggie's (2008) addition of two disciplinary (marketing) journals to the more standard set of core IB journals provides a good example. An analysis of publications in the two added international marketing journals (IMR and JIMar) reveals that the university that ranked first in Xu et al.'s (2008) assessment, Michigan State, out-published all other universities in these two journals, with nearly three times more articles than 2nd-ranked University of Texas and 3rdranked Old Dominion University. As measured by publications in these two journals, Michigan State is clearly the top university in international marketing. But is Michigan State the overall top university in IB, as implied by their place at the top of Xu et al.'s ranking? When only the more recognized core ISI-listed IB journals (JIBS, JWB and 2 years of $I B R$ ) are analyzed over the same period, the highest ranked universities are the Chinese University of Hong Kong (ronked 6th by Xu et al.), the University of Texas (ranked 12th [Dallas] and 16th [El Paso], respectively, by $\mathrm{Xu}$ et al.), and the University of South Carolina (tied for 17th by Xu et al.). Firstranked Michigan State drops to a tie for 6th with two other universities. Whereas each of these universities should be recognized for their contributions to scholarship, especially when viewed through the prism of journal-based productivity measures, their specific positions in the rankings are highly dependent on which journals are included and on the larger issues of breadth and multidisciplinary perspective.

\section{Why View International Scholarship as a Subset of Domestic Scholarship?}

The distinction between general IB journals and those journals focusing more norrowly on a particular discipline obfuscates a more fundamental distinction. IB research-and practice-should not be considered a subset of "general" or "mainstream" business research (which traditionally, yet implicitly, has been defined as U.S. domestic research).
Rather, domestic research is always a specific case (and thus a unique subset) of international research. Using geography as an analogy, a single country is a subset of the world, not vice versa. By excluding "mainstream" journals from IB rankings, which is still common today, IB scholars who publish in such journals are rendered invisible: their rankings as IB scholars are diminished.

Fortunately, the internationalization of the "mainstream" has already begun. Although rare in the past, IB research is increasingly published in top "mainstream" disciplinary journals (Werner \& Brouthers, 2002). Using a very broad definition of international, nearly half of the articles published in $A M J$, for example, are now classified as international (Kirkman \& Law, 2005; see also Tung \& van Witteloostuijn, 2008; Tsui, 2007; Adler \& Bartholomew, 1992, and Boyacigiller \& Adler, 1991). The influence of IB research published in top "mainstream" journals is also increasing. Griffith et al. (2008), for example, found that the 15 most cited IB articles in $A M J, A M R$, and SMJ received nearly twice as many citations as did the 15 most cited articles in all six top IB journals. Similarly, the most highly cited works in articles published in the three leading IB journals were more likely to come from "mainstream" management journals than from IB journals. Whereas not true in the past, "mainstream" is becoming the definition of international scholarship in the 2lst century.

Choosing journals on which to base a ranking clearly establishes who the field identifies as the winners and losers. Small changes in the set of journals lead to dramatic changes in the rankings. Definitional discrepancies, most strikingly between mainstream and specialist journals, and between multidisciplinary journals and those more narrowly focused on within-discipline scholarship, skew the resulting rankings to the point of meaninglessness. Moreover, as will be discussed in the following sections, the lack of clarity and consistency in assessing the distinct dimensions of quantity, quality, and impact undermines the value of all current ranking systems, no matter how broadly or narrowly defined. Both through implicit and explicit influence, competition among universities to improve their rankings-based reputations compels individual scholars to direct their research toward A-listed journals. Whereas reputations may be enhanced, scholarship suffers. Given the arbitrary nature of the range of decision criteria used to construct our current ranking systems, the field must seriously question if such metrics are capable of accurately and fairly recognizing researchers, and of supporting the types of scholarship that matter most to the world. 
Āssessing Quality: Journals Fail as Proxies for Article Quality

"Using journal rank as a proxy for quality can lead to substantial judgment errors: Many top articles are published in non-top journals, and many non-top articles are published in top journals." —Singh et al. (2007: 321)

How does one measure the quality of scholarship, and, by extension, the accomplishments of individual scholars? Management, like other disciplines, has identified a set of top journals to serve as proxies for quality (see, among many others, Singh et al., 2007; Franke, Edlund, \& Oster, 1990; Johnson \& Podsakoff, 1994; Podsakoff, MacKenzie, Bachrach, \& Podsakoff, 2005). Many scholars argue that the quality of a journal reflects the quality of the articles published in that journal. It has become common to refer to a scholar's worth by saying that he or she has two AMJs, three JIBSs and one ASQ. Without ever mentioning the content, quality, or impact of the article itself, the implication is that the scholar must be good.

Starbuck (2005: 180), in an extensive statistical analysis, found "that there is much overlap in [the quality of] articles in different prestige strata" of journals. Based on a comparison of the quality of articles with that of the journal in which they are published, Starbuck (2005: 197) discovered that over 50\% (ranging from 29\% to $77 \%$ ) of articles published "in the first quintile of journals do not belong among the highest-value $20 \%$ of manuscripts." "Although higher-prestige journals publish more high value articles, editorial selection involves considerable randomness. Highly prestigious journals publish quite a few low-value articles, low-prestige journals publish some excellent articles..." (Starbuck, 2005: 196). Starbuck (2005: 196) concluded that "Evaluating articles based primarily on which journal published them is more likely than not to yield incorrect assessments of the articles' value."

Based on an analysis of 7 years of citations to every article in 34 top management journals published in 1993 and 1996, Singh et al. (2007: 327) drew the same inescapable conclusion: "[U]sing journal ranking ... can lead to substantial misclassification of individual articles and, by extension, the performance of the faculty members who authored them." Type I and Type II errors are rampant. Based on Singh at al.'s (2007) use of the median number of citations in the top 34 management journals as a threshold, nearly half of the articles published in the top-34 management journals failed to meet the standards for being classified as top articles (48\% in 1993 and $45 \%$ in 1996). If the mean, rather than the median, number of citations had been used, the proportion of non-top articles published in the top-34 management journals would have risen to over two thirds $(68 \%$ in 1993 and 69\% in 1996). The consequences of using journal quality as a proxy for article quality are a matter of concern for both the field and individual scholars.

Based on their research, Singh et al. (2007: 319) warn that "both administrators and the management discipline will be well served by efforts to evaluate each article on its own merits rather than abdicate this responsibility by using journal ranking as a proxy for quality." This is a particularly important recommendation today when an increasing number of universities either require publications in the top three to five journals in a scholar's discipline or completely disregard publications in journals outside of those few identified as "top" (Singh et al., 2007; Van Fleet, McWilliams, \& Seigel, 2000; AACSB, 2003). Whereas there may be reasons to use journal rank as one indicator of article quality, there is no reason to use it as the only or even the best measure.

Lawrence (2003: 261) unambiguously recommends that "we can all start to improve things by toning down our obsession with the journal. The most effective change by far would be ... to place much less trust in a quantitative audit that reeks of false precision." Lawrence (2002: 835) urges academia to "stop measuring success by where scientists publish and [to] use different criteria, such as whether the work has turned out to be original, illuminating and correct." Starbuck (2005: 196) likewise concludes that those evaluating scholars for promotion and tenure need to stop ignoring the randomness of article placement in journals, and more importantly, stop basing evaluations "on one myopic measure." Bennis and O'Toole (2005) similarly worry that the current emphasis on journal rankings is directly responsible for retarding the publication of relevant management knowledge. Scholars seeking to publish in top journals "tend to tailor their choice of topics, methods, and theories to the perceived tastes of these journals' gatekeepers. A likely result ... is stagnation in the advancement of management knowledge and a disconnection from the needs of the business community" (Bennis \& O'Toole, 2005). 
Assessing Influence: Being Prolific Doesn't Guarantee Impact

$$
\begin{array}{r}
\text { Do "we now consider the journal to be more } \\
\text { important than the scientific message"? } \\
\text {-Peter Lawrence (2003: 259) }
\end{array}
$$

The confusion between productivity (number of publications) and impact (citation counts) provides another conundrum. The two dimensions are different and yet they are rarely viewed as distinct or appropriately weighted in rankings. For example, of the ten most cited articles in JIBS between 1996 and 2006, only two were written by IB scholars identified as most prolific by Xu et al. (2008). Peng and Zhou's (2006) work on global strategy research and Harzing's (2005) research on Australian academics similarly concluded that being prolific does not necessarily equate with having an impact.

Most rankings also falsely assume that having an impact is based on publications in top journals. To expose this illusion, we use our own records. Among Adler's more than 100 publications, her single most cited work-with well over 2,000 citations in Google Scholor-is not a journal article, but a book, International Dimensions of Organizational Behavior (2008c). Similarly, none of Harzing's three most cited publications are articles in A-listed journals. All three-an edited textbook (with over 300 citations), a research monograph (with over 150 citations), and an article in IJHRM ${ }^{1}$ (with over 130 citations) - would be rendered invisible by the currently used, ISI-based assessment systems. Such occurrences, often falsely labeled as aberrations, again force us to question if the metrics we are using are capable of accurately and equitably recognizing significant research or supporting research that would matter most to society.

\section{Choice of Time Period: Finding Logic Beyond the Arbitrary}

Another crucial aspect of ronkings is the time period on which they are based. To date, there has been little discussion and no consensus as to what constitutes an appropriate time period on which to base rankings (especially when assessing universities). Few studies provide a substantive justification for the time period(s) studied.

Several IB researchers (Inkpen \& Beamish, 1994; Kumar \& Kundu, 2004; Chan et al. 2006), for exam-

\footnotetext{
${ }^{1}$ Although IJHRM is now ISI-listed, it was not at the time of publication.
}

ple, have attempted to examine developments in the field by splitting an overall time period into subperiods. While potentially interesting as an indicator of change, and perhaps progress, such subperiod comparisons usually lack sufficient stability to provide valid results, primarily due to relatively few within-period observations. These comparisons are further confounded by the many scholars who change institutions within the studied time frames.

Rankings are problematic if they are based on relatively few observations (as when a single journal is studied or the time period is short). Inkpen and Beamish's (1994) institutional-ranking study provides an example of this potential instability. The authors chose to divide their 25-year study into two periods (1970-1982 and 1983-1994). The rankings produced by these unequal time periods were substantially different. Based on adjusted numbers of publications, Colombia University ranked lst in the initial period, but only 27th in the later period. The University of Wisconsin, which ranked 3rd in the initial period, failed to have a single publication in the later period. The University of South Carolina, which ranked lst by a wide margin in the later period, only tied for 8th in the earlier period. The University of Western Ontario ranked 2nd in the later period, but was 2 nd to last in the earlier period.

Inkpen and Beamish are not alone in having uncovered instability. Chan et al. (2006), for example, in splitting their time frame into two 5-year periods (1995-1999 and 2000-2004), also discovered significant variability. The University of South Carolina, for example, improved its ranking from 30th in the initial period to 3rd in the subsequent period; The University of Western Ontario dropped from $3 \mathrm{rd}$ in the initial period to 36th in the ensuing period. The University of Texas-Austin dropped dramatically from 10th to 155th, while The University of Hong Kong gained 100 places, rising from 121 st to 21 st place. Such dramatic instability forces us to question the extent to which such rankings are meaningful.

Reviewing institutional rankings not only reveals instability across arbitrarily set time periods, it also exposes a more fundamental problem. Rankings reported as institutional generally only reflect the productivity of each university's most prolific scholar(s). To highlight just one of many examples, in Kumar and Kundu's (2004) decadelong study, The University of Bradford, the highest ranked non-North American institution, placed 6th out of 40 in the initial 5-year period (1991-1995), and yet failed to make the top 40 after 1995. Rather than being an aberration, this striking result most likely 
reflects prolific author Peter Buckley's move from Bradford to Leeds in the second half of 1995. Not surprising, given Buckley's move, the University of Leeds appeared from seemingly out of nowhere to be ranked 12th in the later 5-year period.

Whereas these radically fluctuating results in part reflect the expected variability within most disciplines, they more ominously expose the flaws in the underlying ranking systems. In most cases, rankings that purport to measure universities' productivity are actually false aggregations from the individual to the institutional level, rather than a measure of the university's current or future ability to contribute to the discipline or society. Data with such extreme variability cannot reliably be used to meaningfully rank anything, and certainly should not be used to assess the worth, or lack thereof, of one university relative to another.

\section{Weighting the Data: $\bar{A}$ Confounded and Contentious Business}

"As so often happens with indicators of performance, the indicator has become the target ... All but forgotten in the desperation to win the game is publication as a means of communicating research findings for the public benefit." -Macdonald \& Kam (2007: 702)

Those who construct ranking systems must not only choose which categories of publications to include, but also decide on how to weight publications based on journal prestige and authorship criteria.

\section{Prestige: What Is Most Valuable?}

Is publication in a field's top-ranked journal(s) more valuable than publication in a journal of lesser rank? Some IB scholars, for example, argue that an article in JIBS is more valuable, and therefore, should be more heavily weighted, than articles in other journals. Both Dubois and Reeb's (2000) ranking and Harzing and van der Wal's (2008a) citation-based analyses demonstrate that JIBS is in a league by itself in terms of influence in international business. JIBS's elite status is further confirmed by its standing as the only IB journal recognized as "mainstream" in the most prominent lists of A-level management journals (i.e., in the FT40 and UTD lists). Based on its 2007 ISI journal impact factor, JIBS was ranked as one of the top-7 business journals in 2008.

To date, no study has chosen to employ a grad- uated, prominence-based weighting system for their rankings. Most current rankings continue to be winner-take-all systems, with authors receiving equal credit for articles published in selected "Alist" journals and receiving no credit for articles published in nonlisted journals or for books, book chapters, or conference proceedings. As a field, we must ask if such binary metrics (on or off the A-list) enhance or detract from the discipline's ability to recognize and support research that matters or even to accurately and equitably assess the contributions of individual scholars and institutions.

\section{Invisibility: Research Published in New, Innovative and Specialized Journals}

Many subdisciplines are underrepresented in the databases used to calculate the most commonly used, and supposedly "objective," measure of journal "quality": the ISI journal impact factor (which actually measures influence, not quality). This is particularly true for journals in accounting, management, marketing, strategy, and IB (Harzing \& van der Wal, 2008b).

Perhaps more important, new (often highly innovative) journals are systematically excluded from the rankings. The ISI Social Science Citation Index enforces a mandatory 3-year "waiting period" for all new journals. Once accepted for inclusion, there is a subsequent 3-year "study period." Thus, at the earliest, a journal can receive its first official impact factor (IF) in the Journals Citation Report 6 years after its inception.

Because articles published in new journals remain invisible to most citation indices, they also remain invisible to almost all ranking systems. Such invisibility dramatically skews scholarship, as it implicitly encourages conservative research that asks familiar questions using accepted methodologies rather than research addressing new, often controversial questions that are investigated using innovative methodologies. This bias is particularly unfortunate today, when understanding the rapid, discontinuous changes that characterize business and society demands constant innovation. The contention that much academic research is rigorous but irrelevant is fostered by what the existing ronking systems leave out.

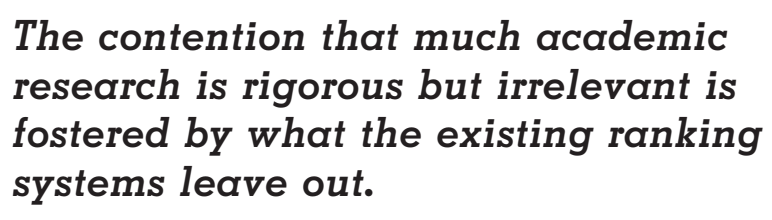

The contention that much academic research is rigorous but irrelevant is fostered by what the existing ranking systems leave out. 
The consequences of the current winner-takesall system and its explicit bias against new journals con be appreciated through the experience of one of this article's authors. Adler published on article in 2006 in Academy of Management Learning and Education (AMLE). Launched in 2002, AMLE only qualified to be included in the Thomson Reuters ISI Journal Citation Report in 2008. After Adler's article was selected as one of the top-3 articles published by $A M L E$, she was "amused" to learn that her university's 2007 Merit Committee had chosen not to credit her with the publication, and had docked her pay accordingly. And yet, the 2007 impact factor for this new journal (which was first released in June 2008) was 2.796, ranking it 7th in management, in the same league with such consistently A-listed journals as Strategic Management Journal (2.829) and Administratively Science Quarterly (2.912). ${ }^{2}$ Only after presenting the Merit Committee with on "as if" ISI impact-factor for this new and at that time as-yet-unrated journal did the committee suddenly become capable of "seeing" the article and appreciating its value; only then did they grudgingly grant the legitimacy of a merit-based pay raise. Such systems make it dangerous, especially from the perspective of pay, promotion, tenure, grants, and prestige to publish research, no matter how good, in new and innovative journals. It is therefore difficult to understand how such a metric could do anything other than undermine the system's ability to render accurate and fair assessments or to support research that matters.

\section{Weighting Single Versus Multiauthored Articles: No, It Is Not All the Same}

Another decision is whether to assign equal weight to authors of single- versus multiauthored articles. Whereas there are advantages to both approaches, bibliometricans now generally agree that fractional equivalents are more equitable and appropriate (Gauffriau \& Larsen, 2005). Fractional equivalents are calculated by assigning $1 / n$, where $n$ is the number of authors, for each article an author has written. Fractional equivalents are now favored in most, but not all, ranking studies, and

\footnotetext{
${ }^{2}$ The journal impact factor, or JIF, is the mean number of citations received in a particular year to articles published in a journal in the preceding 2 years. Thomson Reuters ISI does not make the exact formula for calculating JIFs public. AMLE's reported JIF was within .033 of that of SMJ and .116 of ASQ, meaning that approximately only one in 30 articles in SMJ and one in 9 articles in ASQ received one additional citation. Many observers would consider such differences to be negligible.
}

an increasing number of universities recognize that promotion-and-tenure decisions are most justifiably based on fractional equivalents rather than simple article counting.

Overall, differences in productivity assessments among universities are generally smaller when fractional equivalents are used. In the most recent IB ranking, for example, Xu et al.'s (2008) use of fractional equivalents for authors, but total publication counts for institutions, illustrates how such on unconventional choice can skew and potentially confound the rankings. As shown in Figure 1, compared with $\mathrm{Xu}$ et al.'s approach, using fractional weightings would have significantly reduced the lead of lst-ranked Michigan State University over 2nd-ranked Leeds University. The reason is evident: Michigan State has the highest average number of authors per article (2.5) among the top-10 ranked universities. Similarly, with fractional weightings, The University of Reading would move up from a tie for 4th to 3rd place, reflecting Reading's tendency toward single-authored articles (average: 1.4 authors per article). More dramatically, The University of Miami would move up from 9th to 5th place, primarily due to the large number of single-authored publications by $\mathrm{Mi}$ ami's one prolific IB scholar, Yadong Luo.

\section{Weighting the First Author: Recognizing Leadership}

A similar decision is whether to give more weight to the first author of a multiauthored article. Most ranking studies, unfortunately, continue to systematically ignore whether an author of a multiauthored article is listed first. Authors (and their affiliated universities) who are frequently listed last on multiauthored articles therefore could be viewed as prolific, even though they have never provided research leadership. At the individual level, this is particularly serious as all advances in scholarship, including frome-breaking research, depend on individuals assuming leadership. While it can be argued that this problem manifests itself only at the individual level, as aggregating and averaging across individuals at the institutional level mitigates the effect, this reasoning is flawed, as institutions vary widely in the average number of authors per published article. Given the arbitrariness of current weighting decisions, we must question how meaningful the resulting rankings are, or could ever be. 


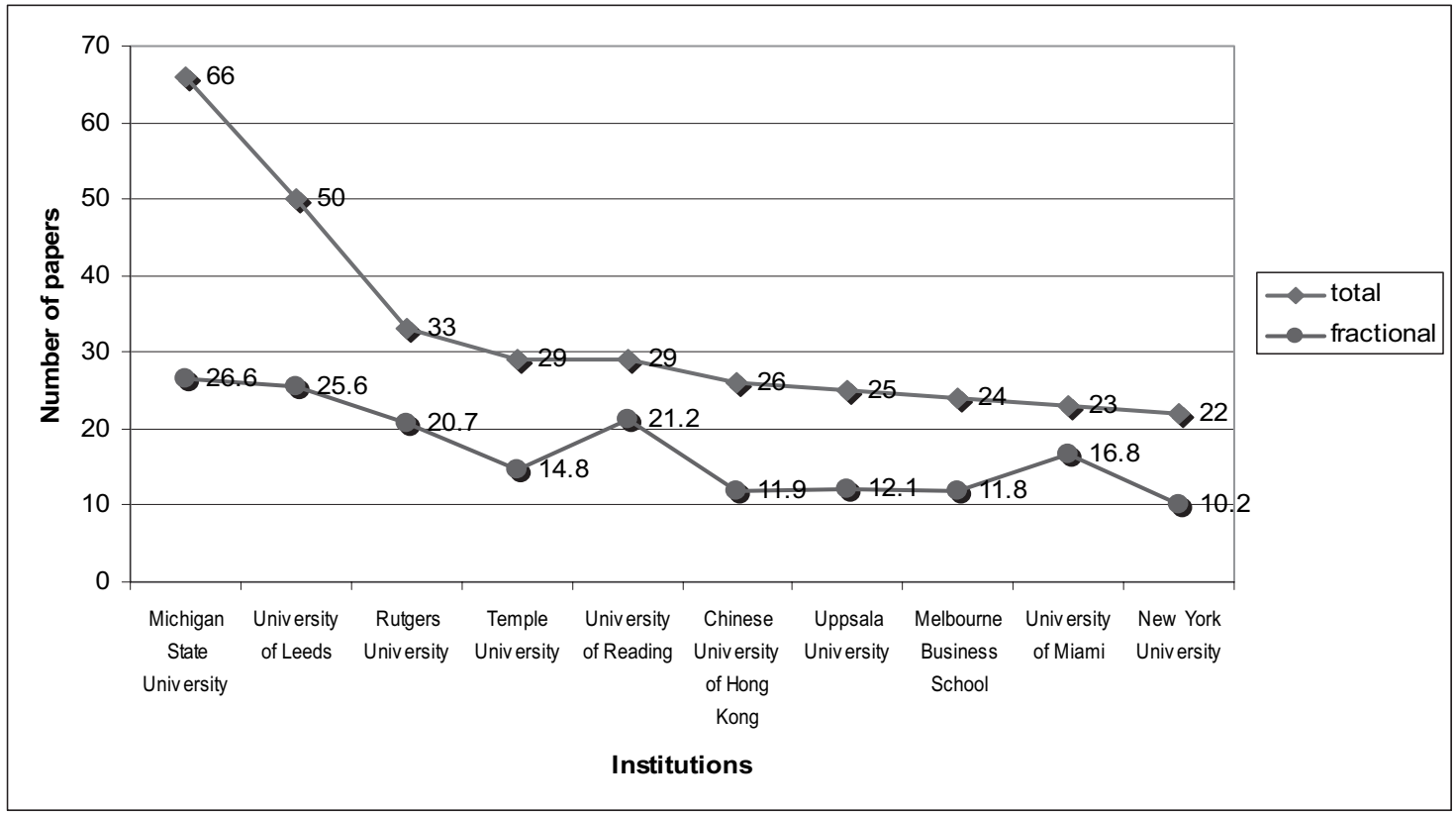

FIGURE 1

Top-10 Institutional Ranking Based on Total Versus Fractional Number of Articles

\section{Aggregating to the Institutional Level: Institutional Ronkings Don't Reflect What They Purport to Reflect}

A final important decision, specifically for institutional rankings, is the way in which individual productivity is aggregated to the institutional level. We have seen striking examples of how the move of a single prolific scholar, such as Luo or Buckley, can catapult a university into or out of the top ranks. Of the 81 institutions listed in the most recent IB rankings, for example, less than a quarter have more than one prolific author (Xu et al., 2008). The nomadic behavior that is commonplace among prolific scholars makes institutional rankings unstable at best and meaningless at worst. In addition to the problems caused by prolific nomads, at least five other serious challenges threaten the validity of institutional rankings.

\section{Multiple Name Variants Undermine Rankings: $A$ Transnational Challenge}

Today, just at the time when scholars most need to understand research contributions from around the world, name-variant biases systematically undervalue the work of scholars located in non-English speaking countries. Scholars working in languages other than English frequently publish under multiple nome varionts of their university or department. Researchers affiliated with Wirtschaftsuniversität Wien, for example, may publish under either their university's German or English name (Vienna University of Economics and Business Administration).
Ranking systems, however, often do not recognize the two names as representing the same institution. Mangematin and Baden-Fuller's (2008) recent ranking used a time-consuming manual verification process to ensure correct affiliation and aggregation. Most other rankings skip this inefficient process and rely on raw ISI or Google Scholar data. As a result, they risk seriously underestimating the contributions of universities with multiple, non-English names. The higher ranking of Asian and European institutions in Mangematin and BadenFuller's (2008) study is likely due in part to their more careful multilingual-affiliation-attribution methodology. The challenge is to ensure that scholarship from around the world is not only fairly and accurately reflected in the rankings, but also, and more important, that it is accessible and recognized as valuable. Given today's global business and societal dynamics, the illusion that only English-speaking scholars and institutions produce valuable, trend-setting research is completely misleading, and ultimately dysfunctional.

\section{Who Gets Credit? Aggregating Across Multiple Campuses of the Same University}

Are campus-by-campus or overall-university rankings more appropriate at universities with multiple campuses? As yet, this question has no agreed-upon answer. Xu et al.'s (2008) IB ranking provides on example of the complexity. Although Thomson Reuters 
ISI's Web of Knowledge aggregates all University of Texas campuses, Xu et al. (2008) separated them. As a result, The University of Texas at Dallas ranked 12th and The University of Texas at El Paso ranked 16th. If these two campuses had been combined, The University of Texas would move up to 4 th place. The University of Melbourne also appears twice in Xu et al.'s (2008) ranking, once as Melbourne Business School (MBS) and a second time as The University of Melbourne (referring to Melbourne's Department of Management and Marketing in the Faculty of Economics and Commerce). Whereas rankers could easily make a case for separating the two departments, The University of Melbourne would obviously prefer that they be combined, arguing that the University houses one major IB center with professors working at two locations. Using the University's preferred approach, Melbourne would move up from 8th to a shared 4th place, and could rightfully claim to be the highest ranked university in the Asia Pacific region. The inherent problem with such influential, and often politicized, decisions is that they render the rankings as arbitrary, and thus meaningless.

\section{Who Gets Credit? Scholars With Multiple Affiliations}

Another aggregation conundrum is how to assign credit for academics with multiple affiliations. Surprisingly, most rankings credit the full number of articles published to each institution with which an author is affiliated. A more equitable system than double counting would favor the same type of weighting scheme as is used to assign partial credit to the multiple authors of a single article. However, focusing on how to equitably credit universities with the productivity of scholars with multiple affiliations masks an underlying, and much more serious, problem. For many universities, the rankings have unfortunately-but, from certain perspectives, understandably-become an end in themselves. One need only observe the recent pattern of increasingly frequent "visiting professorships" to recognize this dysfunctional dynamic. Some universities now offer extremely generous packages to highly productive scholars to attract them as special visiting professors. The only proviso is that the visiting scholars agree to list their new dual affiliation on all their publications, even if they spend only a few weeks each year at the host university.

How does the ability to appropriate a scholar's productivity affect that scholar's choice of research topic and focus? Does it support or undermine scholarship that matters? Can "bought productivity" meaningfully be handled in the rankings? How should the field respond if we see a further escalation of affiliations, in which particularly prolific scholars simultaneously hold five or ten simultaneous appointments? Should guest-scholars who only spend a short time at a host university have their publications used to enhance that university's ranking, and thus its reputation? What algorithm for fractional weighting would be fair? Without addressing these questions, institutional rankings will continue to move toward meaninglessness (if they are not already there), and individual scholors will increasingly be drawn toward research programs that are most likely to produce the most enticing set of multiple affiliations. In Merton's (1936: 897) terms, this is a clear case of a dysfunctional "unintended consequence," or in Kerr's (1975: 769) terms of having fallen prey to "folly" "of rewarding A [publications in a narrow set of top-listed journals] while hoping for B [scholarship that addresses the questions that matter most to society]".

\section{Who Gets Credit? Current University or University at Time of Publication?}

Another similar conundrum is how to assign university affiliation: based on current affiliation or on the scholar's affiliation at the time a paper was written and/or published. Unlike most economics rankings (Macri \& Sinha, 2006), most IB rankings credit the scholar's university at the time of publication. Using current affiliation purports to identify institutions that are most likely to produce the greatest academic impact in the future. However, it implicitly assumes that prolific authors will cease to be nomads and will not move on to yet another university. The choice of how to assign credit has important implications for the majority of universities with few prolific researchers. The University of Miami, for example, would not have achieved a high ranking from Xu et al. (2008), who chose to use current affiliation, if Luo, Miami's only prolific IB researcher, had had his earlier publications, produced while he was in Hawaii, counted toward Hawaii instead of Miami. The central issue, of course, is if such rankings, based on scholars' nomadic behavior, are meaningful, let alone helpful.

\section{Inclusivity: All Authors or Just the Most Prolific?}

A final decision is whether to include all scholars working at a given university or just the most prolific. Whereas one could certainly make an argument for focusing only on scholars who have published a substantial body of work, such a choice would not reflect the breadth and stability of researchers that most universities need to maintain 
major research programs (and, by consequence, their place in the rankings). Xu et al.'s (2008) inclusion of only prolific authors highlights the risk of such metrics producing highly idiosyncratic rankings. Although Wharton ranked 4th and INSEAD 6 th, based on the total number of articles published in JIBS for the assessment period, neither institution appeared among the top 81 universities when $\mathrm{Xu}$ et al. included only the publications of prolific authors. Such variability underscores the fact that, given the "right" choice of journal(s), time periods, and rules for weighting and inclusion, almost any university can be crowned a winner or relegated to loser status. When any level of ranking becomes possible, no ranking remains meaningful.

\section{DISCUSSION}

$$
\begin{array}{r}
\text { "... when we, as academics, plead power- } \\
\text { lessness in choosing what we research ... } \\
\text { because of incentive and reward systems..." } \\
\text { we dehumanize our careers and our lives." } \\
\text { - Sara L. Rynes, Editor-in-Chief } \\
\text { Academy of Management Journal (2007b: 747) }
\end{array}
$$

The proliferation of and increasing reliance on volatile, arbitrory assessment systems portends an ominous future for academic rankings and their ability either to accurately and equitably assess individual or institutional performance or to recognize and support scholarship that matters. Based on the present situation, we recommend that academia ( $\alpha$ ) institute a temporary moratorium on institutional rankings; (b) attempt to better understand and subsequently address the macrolevel dynamics that implicitly collude in keeping such dysfunctional ranking systems in place; (c) redesign individual rankings to render them more globally inclusive, accurate, and equitable; and (d) create environments that foster and appreciate excellent scholarship on the questions that matter most to business and society. In all four areas, scholars and institutional actors from around the world are invited to offer their global and multidisciplinary insight and experience to help design and implement approaches that will be more effective than the leftover 20th-century systems that, unfortunately, remain in place today.

\section{A Temporary Moratorium on Institutional Rankings}

We recommend instituting an immediate, temporary moratorium on institutional rankings. With universities increasingly resorting to buying resumes and paying significant publication bonuses (at times exceeding $\$ 20,000$ per A-listed journal article), academia needs to guard against rewarding tactics designed primarily to score well on national and international rankings. To witness the dysfunction of the current system, one need only consider the academic job market in the United Kingdom immediately prior to the 2008 Research Assessment Exercise, when the scramble for rankings eclipsed scholarly purpose. The UK job market was likened to a transfer morket for soccer players with top scholors rumored to have accepted their next position even before joining their prior "new" institution. It is not just that ranking systems are inconsistent, volatile, and in many ways inherently unfair; it is also that the motivation systems they engender-including encouraging blatant individual self-interest and a consequent lack of loyalty to any particular university or broader societal mission-undermine the very essence of good scholarship. In addition, such motivation systems lead universities to systematically and corrosively undervalue the importance of teaching and learning. Given the rewards for A-listed publications, they subtly, and not-so-subtly, pressure professors to minimize their commitment to teaching and maximize the time they spend on research activities that generate the highest reputational and financial rewards. Rather than continuing to defend the current system, universities and granting agencies should invest the same time, money, reputation, and energy in designing systems that broadly encourage learning and education through the creation and dissemination of research that matters. In the following sections, we offer a way to understand and approach this transformation.

It is not just that ranking systems are
inconsistent, volatile, and in many ways
inherently unfair; it is also that the
motivation systems they
engender-including encouraging
blatant individual self-interest and a
consequent lack of loyalty to any
particular university or broader societal
mission-undermine the very essence of
good scholarship.

Understanding the Embedded and Mutually

Reinforcing Nature of Academic Ranking Systems: An Institutional Perspective

Given the blatant dysfunction of current ranking systems, why do they continue to exist? The an- 
swer, of course, is that academic rankings are not isolated phenomena. They are embedded within mutually reinforcing organizational and societal environments. Viewed through the lens of institutional theory (DiMaggio \& Powell, 1983; Scott, 1987; Westney, 2005; and Zucker, 1987, among others), academic rankings can be understood to persist because the individuals and organizations that rely on them "adopt patterns that are externally defined as appropriate to their environments, and that are reinforced in their interactions with other organizations" (Westney, 2005: 47).

According to institutional theory, "Organizations, and individuals within organizations, are moved toward isomorphism, the adoption of structures and processes prevailing in other organizations within the relevant environment" (Westney, 2005: 48). Among the network of institutions supporting academic rankings, there appears to be a very high degree of isomorphism. Dominant institutional players form what is referred to as a wellorganized field in which each player is influenced to adhere to similar, mutually reinforcing types of ranking and assessment behaviors. Viewed from this perspective, the current system of academic rankings predictably emerges as an anthropological artifact from within a well-organized field.

Institutional theory allows us to appreciate the highly entrenched, self-reinforcing network of influences and relationships that embed the system of academic rankings and render it, among other things, extremely difficult for isolated individuals and organizations to change. Isomorphism abounds in the systems supporting academic rankings, with the behavior of each category of institution insidiously determining the behavior of organizations in most other categories. There is a very high degree of institutional alignment supporting the current pattern of academic rankings-an alignment that, unfortunately, has evolved into a form of often subconscious, dysfunctional collusion. Major institutional players engage in mutually reinforcing roles. The dominant dynamics reifying the current system include (a) the need for assessment systems to appear accurate, objective, and fair; (b) the desire for systems that will not overwhelm the time constraints of the already extremely busy adjudicators; (c) the quest for credibility and prestige along with the benefits each brings; and (d), given ever-intensifying marketdriven competitive pressures, the need to publicly distinguish oneself and one's institution. Below are a range of institutional examples highlighting the ways in which the network of organizations that influence academic rankings has adopted "patterns that are externally defined as appropri- ate to their environments, and that are reinforced in their interactions with other organizations" (Westney, 2005: 47); that is, how the network of institutions involved in academic rankings exhibits the high levels of isomorphism commonly found in highly collusive, well-organized fields.

\section{Research-Granting Agencies}

Primarily due to the very public nature of the funds they distribute, national and international research-granting agencies know that they must respond to the public's insistence that their money be well spent. In most cases, they respond by claiming "scientific" (meaning to them "quantifiable") objectivity-what March (1996: 286) would refer to as "magic numbers." The agencies also know that they must be responsive to the demands for an efficient process from the tremendously busy grant adjudicators (most of whom serve as unpaid professional volunteers). Counting publications in A-listed journals meets both criteria; it is an easily understood and quickly quantifiable metric that appears objective to the broader public.

Further reinforcing the current system is the proclivity of granting agencies to select prior grant winners to adjudicate current grant proposalsscholars who, not surprisingly, are most inclined to support the very rules that led each of them to receive their own, frequently sizable, grants. The winners in a particular system, having reaped the benefits of that system (in this case, the money, prestige, and career advancement that comes with receiving research grants) are most likely to consciously or subconsciously internalize the system's underlying assumptions and values, and are, therefore, least likely to question the efficacy of the system they have publicly benefited from and have agreed to uphold. More broadly, many scholars who need continued funding for their own research fear the consequences of rejection if they question or deviate from established norms.

\section{University Promotion-and-Tenure (P\&T) Committees}

P\&T committees operate under pressures similar to those influencing research-grant agencies. P\&T committees are generally staffed by "busy volunteers" (professors who generally are not given extra pay for the hours they spend reviewing their colleagues' files), who seek ways to evaluate candidates that appear (to them and to others) objective and fair and which do not consume inordinate amounts of time. Counting the number of publications a candidate has in A-listed journals (as op- 
posed to the much more time-intensive and inherently subjective process of reading and evaluating each candidate's entire portfolio of work) superficially achieves both requirements. Assessing books is particularly problematic, as they are generally too long to reasonably expect most committee members to read. Moreover, even the presses recognized for publishing books with some of the best scholarship are not consistent in their review and selection procedures. In addition, given that in most cases, the same system anointed the members of the P\&T committee themselves with the prestige, career security, and financial rewards of promotion and tenure, they are unlikely to judge the system they personally benefited from as illegitimate.

The isomorphism becomes equally evident when one considers that many P\&T committees, as well as annual-merit-review and selection-and-hiring committees, include professors' research-grant records as one of the indicators of academic performance. Having adhered to very similar underlying assumptions, most P\&T committees have no trouble accepting the decisions of the researchgranting agencies as legitimate input into their own decision-making processes.

In its more pernicious form, senior faculty members support their own status and control the behavior of junior colleagues by forming their own A-lists that, not by coincidence, often include journals in which they personally publish, serve as editorial board members, and/or support the publication records of favored candidates. The authors learned of a revealing example of this apparent behavior at a management school in a top-ranked research university in North America. At this particular university, a journal that had had an impact factor below 0.5 for the first 4 years of the decade was included on the university's newly created 2008 A-list of management journals. A JIF below 0.50 means that, on average, less than one in two articles in this newly A-listed journal had been cited in anyone's publications in ISI-listed journals in the 2 years following publication. Over the past 2 years, the newly included journal's JIF has risen markedly, peaking recently at $\sim 2.5$. Thanks to the journal's higher JIF, it had achieved top ranking in its category in each of the past 2 years, after having hovered around 40th for much of the earlier period. Such variability is not only one of the inherent problems with using the JIF to assess individuals, journals, and universities, but also one of the reasons that such metrics are so vulnerable to manipulation.

Whereas the above description initially appears to present a success story (and therefore an appro- priate choice for citation-based A-lists worldwide), closer inspection reveals that much of the increase in the newly listed journal's JIF appears to have come from an extremely rapid increase in journal self-citations; that is, from articles in the journal citing other articles in the same journal. While the average proportion of self-citations in the newly listed journal was $13 \%$ in the earlier period, it rose to $65 \%$ in the later period. In comparison, an established, highly ranked journal in the same category had a self-citation rate of $7 \%$ for the earlier period and $13 \%$ for the later period. The newly listed journal thus had five times the proportion of selfcitations as the more established journal. Although the specific reason for the escalation in self-citations is not publicly available, such dramatic increases are often symptomatic of the editor and/or editorial board members playing the rankings game; that is, strongly encouraging authors during the review process to cite other articles in the same journal. Although researchers have yet to document how pervasive the practice of requiring journal self-citation is as a subtle or explicit precondition for publication, informal reports of such behavior are increasing. The fact that none of the research-committee members who selected this particular journal for the university's new 2008 Alist questioned the process exposes the power of the current norms, the isomorphic pressures, and the institutionalized vulnerability to manipulation.

\section{Academic Journals}

Journals also benefit from winning in the rankings, as being labeled as A-level confers prestige on the journal and its editor. The flurry of congratulatory e-mail exchanged among editorial board members when their journal receives a high JIF exposes the underlying dynamic. Similar, but more disturbing, is the pressure exerted on editors to explain drops in their journal's JIF, even when their editorial policy explicitly targets broader populations than just academics. For example, the editor of Human Resource Management, a journal whose goal is to publish high-quality research with on impact on practice, found herself required to explain why $H R M$ 's JIF had dropped from a miscalculated (see Harzing \& van der Wal, 2008b) average of 2.0 in 2002-2006 to 0.64 in 2007.

An equally important dynamic, given the pressure on scholars to publish in A-listed journals, is that the journals achieving A-level status attract ever increasing numbers of submissions. The large number of submissions relative to available space for publication leads to high rejection rates, which is yet another measure frequently used to grant 
status to journals and their editors. Success, as recognized by the avalanche of submissions, presents editors with challenges similar to those faced by research-grant agencies and P\&T committees. How do editors and their editorial board members appropriately assess the increasing volume of submitted manuscripts? Given the public nature of acceptance-versus-rejection decisions, their career-defining consequences for individual authors, and status-defining consequences for the authors' universities, along with the unpaid ("professional volunteer") nature of academic-journal reviewing, the pressure has mounted to use assessment methods that appear accurate, objective, and fair, but are not too time consuming. Unfortunately, as has been documented previously, the output of the current manuscript-reviewing system is inconsistent (including relative to impact): Some articles that are published in A-listed journals receive relatively few citations, whereas a proportion of the articles rejected by A-listed journals and published in lower ranked journals eventually receive a substantial number of citations. Thus the input into P\&T and research-grant assessments is seriously flawed.

In addition, and perhaps more serious in its consequences, since A-listed journal status is generally conferred based on journal impact factor (a flawed measure of influence) and not on any measure of quality, journal editors and their editorial board members are tempted, if only subconsciously, to favor those articles that are most likely to be cited (as opposed to those qualitatively deemed to be the best or most important). Having personally been overwhelmed by the number of review requests, including having once received 24 requests in one month, we are sympathetic to the pressures on journal editors and editorial boord members in terms of perceived objectivity, efficiency, quality, and impact. The field, however, needs to find better ways to address the challenges these pressures present.

\section{Academic Journal Publishers}

Publishers also implicitly collude with the chase for rankings, but based on slightly different pressures than those experienced by editors and editorial board members. For publishers, achieving high rankings is primarily a marketing tool. Many publishers of highly ranked journals now prominently feature the ISI journal impact factor and ranking on each journal's website. Many publishers have also introduced the on-line listing of prepublication versions of accepted papers (e.g., Springer's and Sage Publication's Online First and
Palgrave MacMillan's Advance Online Publication). Although their stated aim is early research dissemination, an important side benefit for publishers is the potential for additional early citations (and hence higher JIFs ${ }^{3}$ ). The name of Emerald's recently introduced service (EarlyCite) is particularly telling. Neither editors nor authors challenge this practice as they too benefit from the higher circulation generated by such marketing and prepublication in the form of greater exposure and, as a consequence, larger numbers of submissions and citations. There is little incentive for the winners to challenge the current system, and thereby risk reducing the benefits it confers on them. Why would a current A-listed journal, for example, suggest moving from using Thomson Reuters ISI's more parochial ranking system to Google's more globally inclusive system if that very choice could potentially threaten its own standing in the rankings? More threatening to the current lucrative system of publishing academic journals is the move by several leading universities to open-source publishing. Could it be that, while the players in the present system are defending current rankings, free access will substantially undermine their market and thus both their financial and academic power?

\section{Doctoral Programs and Academy-Based Doctoral Consortia}

Like the elders of any tribe, academic elders pass on the wisdom and "tricks" of the culture to the next generation. Rankings provide easy shortcuts to transfer the norms and with them the implicit advice that following the norms leads to success. Many young scholars grow to believe that individual creativity, especially in the form of deviance from academia's current norms, must be delayed not only until after having earned a doctorate and landed one's first faculty position, but, most prudently, until after having received tenure. After having worked for more than a decade perfecting their skills at earning academia's rewards by adhering to its current assessment-based ranking norms, it is unlikely that many scholars will risk

\footnotetext{
${ }^{3}$ At present Thomson Reuters does not include citations to prepublication versions in the calculation of its JIFs. However, given the publishing delays at most journals, nearly all authors are able to change the reference from the prepublished to the published version in their paper's final page proofs. As long as the referring paper is published after the referenced paper (which is true in almost all cases), the citation will count in both the JIF (which is based on citations in the preceding 2 years) and/or the immediacy index (which is calculated based on citations in the same year).
} 
"throwing it all away" by deviating from traditional expectations. The poignancy of this situation is reflected in the fact that most people enter management doctoral programs fervently desiring to address questions that are of the utmost importance to them, not merely to fill a gap in the extant literature using rigorous, but conventional, means (Bartunek, Rynes, \& Ireland, 2006; Vermeulen, 2005). Although to our knowledge no study similar to those focusing on medical students has been conducted on management doctoral students, one would suspect that similar dynamics apply. Students enter medical school passionately committed to idealistic and humanitarian goals. Unfortunately, by the time they graduate, in all too many cases their aspirations have been reduced to attempting to survive a system that regularly makes inhuman demands on them (Becker \& Geer, 1958; Greger, 1999).

Instead of socializing doctoral students into the current chase for A-listed journal publications, why not attempt to fuel their natural desire to make a difference? PhD programs that allow students to combine research training with working on their own research agendas from the beginning of their doctoral studies (as is generally the case in Australia, Canada, and Europe) might have an advantage over programs that require students to complete years of course work prior to embarking on their own research.

\section{Accreditation and Ranking of Business Schools}

In addition to the academic institutions described above, the accreditation bodies for business schools, along with the news and business magazines that publish business-school rankings, all experience isomorphic pressures to conform to the current rankings-based processes. Beyond conferring prestige, rankings have become a key marketing tool for business schools. Most business schools assume that high rankings will increase both the quantity and quality of applicants along with enhancing their prospects for more and higher profile donations. Given the increasing number of business schools worldwide, and the resulting intense competition among them for top students, professors, and funds, business-school rankings are perceived to matter (Khurana, 2007).

One has to question the metrics on which such rankings are based. Do they encourage excellence in business schools' fulfilling their unique purpose in society? Do the increasing resources that business schools use to improve their rankings-such as hiring more career-placement personnel, selecting more media savvy deans, recruiting students from low-salary countries and placing graduates in higher salary parts of the world, and promoting publication in A-listed journals (Segalla, 2008a)act to undermine the university's fundamental purpose? In the isomorphic world of academic ranking, actions such as these are the rational responses of business schools seeking to meet the demands of the market (Segalla, 2008a; Khurana, 2007). Beyond being rational, however, the question such behaviors raise is this: "In which ways, if at all, do such rankings-maximizing behaviors help to recognize and support the research that matters most to society?"

How might rankings, assuming they continue, be used to more positively impact the programs they evaluate? Could, as Segalla (2008b: 3-4) suggests, rankings measure business-school graduates against such criteria as "the number [of graduates] who go to jail for accounting fraud, [the] percentage [of graduates] who manage firms with high product safety recall rates, [the] number working for companies with the lowest carbon emissions, the percentage working for firms with high social responsibility scores, or the correlation between firm bankruptcies and the alma mater of the CEO? [ ... ] Many people, certainly investors, product safety advocates, environmentalist[s], government attorneys, and other concerned citizens, might find these questions much more pertinent" than many of those currently used to assess and rank business schools.

\section{Business-School Accreditation Bodies}

Accreditation bodies such as AACSB also experience pressure from the public to objectively differentiate between the best, good, and not-so-good business schools. As the cost of business school education rises (dramatically so in the United States), public pressure for rankings that distinguish between programs offering the most and the least value-for-money, also rises. Accreditation bodies exert power over business schools, which increasingly feel the need for the public sanctioning that such accreditation offers, by requiring them to meet accreditation-board standards and metrics. Adhering to the same isomorphic pressures as other institutional players in this field, accreditation bodies have adopted publicationcounts, including publications in A-listed journals, as one of their seemingly objective measures. This choice is understandable, and yet not laudable, given that accreditation bodies have neither the time nor the expertise to individually assess every research paper published by each professor. 


\section{Media-Driven Ranking Systems}

The benefits to news magazines-such as BusinessWeek, the Economist, Financial Times, Forbes, McLean's (Canada), U.S. News and World Report, and the Wall Street Journal, among a plethora of others-that publish, and thus publicize, academic rankings are straightforward (Sauder \& Espeland, 2006). Sales of the issues in which the rankings are published are often among the magazines' highest. As described previously, the public wants to know and is willing to pay for what it perceives to be expert opinions identifying those management programs that offer greater value-for-money. In addition, as with any circulation-based dynamic, advertisers are willing to pay more when news magazines achieve higher circulation. Thus both the public and the news magazines superficially receive direct benefits from continuing the current rankings-based assessment systems.

\section{Individual Scholars}

Scholars who seek the visible reputational and financial rewards that come from a successful research-based university career experience extremely strong pressure to play by the rules. Acting alone, no individual scholar or institution is likely to change such a well-aligned system. Coordinated action across individuals and institutions holds a much greater possibility of being effective in altering the highly embedded, self-reinforcing network of influences and behaviors in which academic ranking and assessment has become entrenched. The question facing academia today, therefore, is what form of co-created and/or coordinated action will allow the current rankingsfocused system to reinvent itself into a system that is most able to foster research that matters.

\section{Moving Beyond Dysfunctional Academic-Ranking Systems}

Institutional fields that are as embedded and mutually reinforcing as that of academic rankings are known to be extremely difficult to change. Based on a review of previous research, Sauder (2008) summarizes four processes for bringing about change in such well-defined fields. First, a jolt or exogenous shock "con disrupt the equilibrium of [the] field, [thus] creating opportunities for new field-wide norms, boundaries, and hierarchies to emerge" (Sauder, 2008: 209). As recently as 1988, BusinessWeek's publication of its first ranking of business schools based on customer-primarily student, alumni, and corporate recruiter-satisfac- tion, rather than selected deans' assessments, functioned as a strong exogenous shock to the field (Khurana, 2007). Almost immediately, business schools started to reallocate resources in attempts to achieve "customer" satisfaction (and thus high rankings; Khurana, 2007). In the 21st century, the exogenous shock to the academic-ranking system might be triggered by a dramatic increase in intense competition brought about by emerging economies or the impact of rapid (and relevant) advances in technology. The increasing prominence of Chinese business and scholors, for example, makes it extremely unlikely that today's English-language, American-dominated systems will remain unchanged throughout the 2lst century. Likewise, the similarly rapid and discontinuous advances in globally networked, primarily Internet-based interconnectivity make the continuance of traditional journal-publishing systems and ranking protocols (with their 6-year time-lag on admittance to "the game") almost unthinkable. The question we invite the scholarly community to consider is "How can we take advantage of both predicted and unpredictable 'exogenous shocks' to guide academia toward producing scholarship that is of most value to 21 st-century society?" Whereas institutional theory suggests that exogenous shocks can unfreeze and change embedded fields, it is relatively silent on the leadership needed to leverage such shocks in directions that are most coincident with the fundamental purpose of universities.

According to institutional theory, a second potential source of fieldwide transformation is "changes in organizational logics on a field's established practices and conventions" (Sauder, 2008: 209). The choice to publish this article in $A M L E$, a highly respected journal with a broad and very public commitment to advancing learning systems that enhance the broader society, is, in part, an attempt to begin to alter the field's established practices and conventions. AMLE's readership includes a broad audience consisting of many of the key stakeholders who have helped to maintain the current system-the very people and institutions that could be central to designing and implementing a new, more efficacious system. No change will occur unless the dialogue among stakeholders is compelling enough to begin to alter the underlying organizational logic. $A M L E$ therefore explicitly invited a range of stakeholders to initiate the discussion. Our invitation, however, reaches out to a much larger group beyond the initial set of voices (our own included).

Institutional theory cites evolution as a third way in which embedded fields can change. Grad- 
ual destructuring and restructuring of fields may "be influenced by more general institutional changes over time" (Sauder, 2008: 209). "This comprehensive view of field change... [suggests] how modifications in regulative and normative elements, institutional logics, and the types of actors constituting the field all contribute to a field's evolution" (Sauder, 2008).

A fourth, and potentially very promising way in which fields can change is with the introduction of a new and influential field-level player-what has been labeled an institutional entrepreneur (Hardy \& Maguire, 2008). Sauder (2008) documents how the introduction of U.S. News and World Reports' rankings of law schools significantly transformed the entrenched institutional field for law schools. After decades of virtual "monopoly" by Thomson Reuter Scientific in the field citation analysis, several new players have emerged on the scene. Elsevier's Scopus provides a new source of citation impact measurement that does not fully overlap with Thomson Reuter's Web of Knowledge (see Bosman, Mourik, Rasch, Sieverts, \& Verhoeff, 2006). More important, the introduction of Google Scholar has made the assessment of academic impact more inclusive of research in languages other than English and of policy-oriented research. Free software programs such as Publish or Perish (Harzing, 2008b), providing an easy way to calculate citation metrics based on Google Scholar data, have made impact measurement accessible to everyone with an Internet connection. Although these developments have not yet changed the way academic impact is measured in most institutions, the initial signs of change are evident. In France for instance, the National Center for Scientific Research (CNRS) has requested that all academic researchers provide Google-Scholar-based impact data (using Publish or Perish) in addition to impact data based on Thomson Reuters Web of Knowledge data. What additional new institution-level "entrepreneurs" might enter the field for ranking business schools and scholars? How might such new players be able to shift business schools back toward their fundamental purpose?

Beyond the influence of new players on the field, field-changing institutional entrepreneurship can be exerted by existing players. As Hardy and Maguire (2008) have shown, even the most embedded fields can change if the appropriate rationale, resources, and relationships are established. As summarized in this article and elsewhere, the rationale for changing the current system has already been clearly articulated by a wide range of stakeholders, from individual authors, to deans, journal editors, the business press, and leading
CEOs. All have explicitly expressed the need for management research to be relevant to the problems of the world. The question is, will the field move beyond such eloquent rhetoric and commit resources to action? Will the Academy of Management, for example, invite leaders from each stakeholder group to a search conference designed to redefine and reoperationalize research quality as a multidimensional construct capable of distinguishing well-done relevant research from its shadow opposite? Will the field not only re-examine the relationship it has to real-world problems and opportunities, but also move to collectively support research that matters? These and other questions need to be explored, not simply by a couple of authors from opposite sides of the world, but also by members of the entire community involved in the creation, dissemination, and use of management research.

\section{Improving Individual Ranking Systems}

Although individual rankings are slightly less flawed than institutional rankings, they remain highly problematic. To begin to create a more robust system, designers need to base assessment systems on the quality and overall impact of each scholar's comprehensive body of work. Academia cannot continue to rely on a citation-index system that excludes most ideas presented in languages other than English as well as most scholarship published in books, book chapters, conference proceedings, nonlisted journals, and most new Internet-based outlets. Moreover, in management, as in other professional disciplines, impact needs to be assessed not only among scholars, but rather within both the academic and professional communities of discourse. Although certainly not perfect, Google Scholar provides a database that is more inclusive and appropriate to the distinctively global environment of 2lst century scholarship than does Thomson Reuters ISI (Harzing \& van der Wal, 2008a,b).

Whereas productivity (counting publications) and impact (counting citations) are easier to quantify than quality, quality is potentially more important. Rather than continuing to ignore quality altogether by inappropriately subsuming it into measures of individual- and journal-level impact, or continuing to hope that a single metric might adequately reflect quality, scholars need to collectively generate a wider array of appropriate approaches to recognize quality. Scholars from around the world are therefore invited to begin to identify a range of indicators that could be used to more accurately reflect the quality of their work. 


\section{Scholars from around the world are therefore invited to begin to identify a range of indicators that could be used to more accurately reflect the quality of their work.}

During the transition to a more robust system, we would applaud a proliferation of rankings using varied assessment measures. The resulting abundance would support scholars in combating the current bureaucratization of science caused by an overreliance on a few limited metrics to determine the supposed worth of all scholars and their work. If enough rankings and citation metrics are created, virtually everyone would be able to identify the areas of their greatest strength and contribution. ${ }^{4}$ The field, however, needs to be careful not to draw strong conclusions from any studies based on such transitional assessments and rankings.

\section{Creating Environments That Support Research That Matters}

Former Academy of Management President Bill Starbuck (2007: 24) captured the challenge facing academia:

... researchers have exceptional capabilities, many years of training and freedom to choose how to spend their time. Yet, only 5 to 10 percent of them are trying to benefit someone or something other than themselves.... $[\mathrm{M}]$ any more ... could be making work more enjoyable or productive, ... facilitating more equal distributions of resources within organizations or around the globe,... mitigating environmental degradation, ... [and] inventing better ways to take account of long-term goals in the short term.

What types of environments might universities design to inspire and support scholars conducting research that has the highest potential to significantly advance knowledge and improve society? Would we see more scholastic coaching (the academic equivalent of executive coaching; Morgan, Horkins, \& Goldsmith, 2005; Detsky \& Baerlocher,

\footnotetext{
${ }^{4}$ The collated Journal Quality List (Harzing, 2008a; www. harzing.com/jql.htm) and the Publish or Perish citation analysis program (www. harzing.com/pop.htm) were created based on the same philosophy: provide so many (journal) ranking and citation metrics that everyone can find one that highlights his or her greatest contribution.
}

2007), more globally networked research teams, and more multidisciplinary and innovative co-creation? Would we see discussions among scholars-both those held visibly at conferences as well as those kept hidden behind the anonymity of review processes-shifting from vocabularies of evaluation and critique to vocabularies of appreciation and support? Would universities that offer the most generative environments attract more top scholars than those that continue to entice candidates through more traditional means?

Rather than allowing assessment and ranking systems to continue to consume disproportionate amounts of universities' attention and resources, academia needs to shift to designing and implementing environments that purposefully encourage research that matters. The new theories emerging from positive organization scholarship (POS) offer exciting and heretofore rarely tried approaches to initiating such a transformation (Cameron, Dutton, \& Quinn, 2003; Seligman, 2003). Scholars, for example, might use positive deviance (Spreitzer \& Sonenshein, 2003) to identify the research groups worldwide that have had an exceptionally positive impact on the practice and understanding of management or have been recognized for the extremely high quality of their work. Once identified, other universities could seek to learn from these outstanding outliers-these positive academic deviants-in order to begin to magnify the strengths within their own departments.

Similarly, using the positive lens of appreciative inquiry (Cooperrider, Whitney, \& Stavros, 2003), universities might invite scholars to identify the times when their research was going spectacularly well; times when they felt best about the potential for their scholarship to significantly contribute to their discipline and to society (Adler, 2008a,b). Then after identifying the conditions that allowed them to reach such outstanding levels of performance, the community of scholars could collectively ascertain what it would take for them to more regularly produce at such an extraordinary level. It is perhaps not a coincidence that the organizational behavior department recognized as best by the Financial Times over the past 5 years is dominated by an appreciative approach, rather than traditional ranking- and deficit-based evaluations. ${ }^{5}$ When Peter Drucker asserted that "the task of leadership is to create on alignment of strengths so as to make people's weaknesses irrelevant," he

\footnotetext{
${ }^{5}$ The Organizational Behavior Department at the Weatherhead School of Management at Case Western Reserve University was ranked number one for a composite of the last 5 years.
} 
did not suggest that his organizational advice was applicable to all institutions except academia. ${ }^{6}$

University leaders, including chancellors, presidents, research provosts, deans, and their equivalents, while still constrained by the current institutional environment, have unique opportunities to initiate and leverage change. Taking advantage of his visible position of influence, the new Deputy Vice Chancellor for Research at Melbourne University-stem-cell researcher Peter Rathjen-proclaimed that the main goal of university research is to tackle society's problems (Buckridge, 2008). Rather than emphasizing the university's need to achieve top rankings, he underscored its research mission: to contribute to "both the store of human knowledge and the innovation that will underpin economic advance[s]." He went on to implicitly expose the dysfunctional institutional pressures on the university, including the "challenging research environment made more demanding by the threat of the now defunct Research Quality Framework (RQF)." Policies and statements such as these do much to embed the university's role within the wider societal context.

Whereas all ranking systems implicitly assume that rankings-based competition motivates academics to produce more and better scholarship, no one knows if such narrowly defined competition actually fosters or inhibits good scholarship. Competitive pressure-especially to publish only, or primarily, in A-listed journals-may, in fact, foster attempts to boost scores on assessment metrics, but not necessarily to maximize the quality and significance of the underlying research. Might it be that more generous, collaborative environments inspire and support higher quality research than do environments defined by rankings-based competition? Although we all intuitively suspect that we know the answer, our competitive, deficitbased culture continues to blind us to the consequences of the choices we have been making.

While no individual scholar can change the overall system, each of us can make a contribution by, at the minimum, starting to change the framing of our research conversations from vocabularies of individual success to vocabularies of contribution and significance. Rather than asking colleagues where something was published, we could ask how their research has made a difference and why they continue to be passionate about it. Perhaps at the next Academy meetings, we could describe a newly met colleague as "a professor who has

\footnotetext{
${ }^{6}$ Conversation between Peter Drucker and David Cooperrider in Claremont, California, shortly before Drucker passed away.
}

made a significant contribution by showing that..." rather than repeating the often-used shorthand-of-success and referring to the person as "the professor who has an $A M J$, two $A M R$ s and on ASQ."

\section{The Future of Scholarship: Reclaiming the Patrimony of Nalanda}

The 2lst century needs more international, integrative, interesting, and important research. There is no question that now is the moment in the history of scholarship when we need to return to the fundamental question and ask ourselves, individually and collectively, "What is our scholarship actually contributing?" Historically, the purpose of university-based scholarship was to ask important questions in rigorous ways so that the results could reliably guide society and future research. Tenure, in fact, was institutionalized as a way to support scholars in asking important (and often controversial) questions and reporting even their most unpopular findings without jeopardizing their livelihood. As we create new approaches to assessing how well individual scholars and universities are doing at achieving that historic and worthwhile purpose, we need to be careful not to entrap ourselves in simplistic reductionist approaches. Whether using metrics for counting publications or citations, the question always remains: "Has the scholar asked an important question and investigated it in such a way that it has the potential to advance societal understanding and well-being?"

\section{REFERENCES}

AACSB International (Association to Advance Collegiate Schools of Business) 2003. Ranking the research. Biz Ed, March/April: 11.

Adler, N. J. 2008a. Global business as an agent of world benefit: New international business perspectives leading positive change. In A. Scherer \& Guido Palazzo (Eds.), Handbook of Research on Corporate Citizenship: 374-401. Cheltenham, UK: Edward Elgar.

Adler, N. J. 2008b. International Business Scholarship: Contributing to a Broader Definition of Success. In Jean Boddewyn (Ed.), International Business Scholarship: AIB Fellows on the First 50 Years and Beyond (Volume 13 of Research in Global Strategic Management: 333-343). UK: Emerald Group.

Adler, N. J. (with A. Gundersen). 2008c. International Dimensions of Organizational Behavior. Mason, OH: Cengage.

Adler, N. J. 2006. The arts and leadership: Now that we can do anything, what will we do? Academy of Management Learning and Education, 5(4): 466-499.

Adler, N. J., \& Bartholomew, S. 1992. Academic and professional communities of discourse: Generating knowledge on transnational human resource management. Journal of International Business Studies, 23(3): 551-569. 
Bartunek, J. M., Rynes, S., \& Ireland, D. I. 2006. What makes management research interesting, and why does it matter? Academy of Management Journal, 49: 9-15

Becker, H. S., \& Geer, B. 1958. The fate of idealism in medical school. American Sociological Review, 23(1): 50-56.

Bennis, W., \& O'Toole, J. 2005. How business schools lost their way. Harvard Business Review, 83(5): 96-106.

Bosman, J., Mourik, I. van, Rasch, M., Sieverts, E., \& Verhoeff, H. 2006. Scopus reviewed and compared. The coverage and functionality of the citation database Scopus, including comparisons with Web of Science and Google Scholar, Utrecht: Utrecht University Library, http://igitur-archive. library.uu.nl/DARLIN/2006-1220-200432/Scopus doorgelicht \& vergeleken - translated.pdf, accessed 15 October 2008.

Boyacigiller, N., \& Adler, N. J. 1991. The parochial dinosaur: The organizational sciences in a global context. Academy of Management Review, 16(2): 262-290.

Buckley, P. 2002. Is the international business agenda running out of steam? Journal of International Business Studies, 33(2): 365-373.

Buckley, P. J., \& Lessard, D. R. 2005. Regaining the edge for international business research. Journal of International Business Studies, 36(6): 595-599.

Buckridge, C. 2008. New research head puts focus on tackling society's problems. The University of Melbourne Voice, 2(4): 17 March-14 April 2008.

Butler, K. C. 2006. Finance and the search for the big question in international business. Academy of International Business Insights, 6(3): 3-9.

Cameron, K. S., Dutton, J. E., \& Quinn, R. E. (Eds.). 2003. Positive organizational scholarship. San Francisco: Berrett-Kohler.

Carroll, M. 2008. NIH and Harvard-It's about values, Carrollogos : A blog about Law, Technology, and Music, Wednesday, February 20, 2008 http://carrollogos.blogspot.com/2008/ 02/nih-and-harvard-its-about-values.html.

Chan, K. C., Fung, H., \& Lai, P. 2006. International business research: Trends and school rankings. International Business Review, 15(4): 317-338.

Cohen, P. 2008. At Harvard, A proposal to publish free on web. New York Times, February 12.

Cooperrider, D. L., Whitney, D., \& Stavros, J. M. 2003. Appreciative inquiry handbook. Bedford Heights, OH: Lakeshore Publishers.

Detsky, A. S., \& Baerlocher, M. O. 2007. Academic mentoringHow to give it and how to get it. Journal of the American Medical Association, 297(19): 2134-2136.

DiMaggio, P. J., \& Powell, W. W. 1983. The iron cage revisited: Institutional isomorphism and collective rationality in organizational fields. American Sociological Review, 48(2): 147-160.

Donaldson, L. 2005. For positive management theories while retaining science. Academy of Management Learning and Education, 4(1): 109-113.

Dubois, F. L., \& Reeb, D. M. 2000. Ranking the international business journals. Journal of International Business Studies, 31(4): 689-704.

Franke, R., Edlund, T., \& Oster, R. 1990. The development of strategic management: Journal quality and article impact. Strategic Management Journal, 11(3): 243-253.
Garten, J. E. 2006. Really old school. New York Times, Op-Ed, December 9.

Gauffriau, M., \& Larsen, P. O. 2005. Counting methods are decisive for rankings based on publication and citation studies, Scientometrics, 64(1): 85-93.

Gioia, D. A., \& Corley, K. G. 2002. Being good versus looking good: Business school rankings and the Circean transformation from substance to image. Academy of Management Learning \& Education, 1: 107-120.

Ghoshal, S. 2005. Bad management theories are destroying good management practices. Academy of Management Learning and Education, 4(1): 75-91.

Greger, M. 1999. Heart failure: Diary of a third year medical student. Available on line at http://www.just-think-it.com/ heartfailure.pdf.

Griffith, D. A., Cavusgil, S. T., \& Xu, S. 2008. Emerging themes in international business research. Journal of International Business Studies, 39(7): 1220-1235.

Gulati, R. 2007. Tent poles, tribalism, and boundary spanning: The rigor-relevance debate in management research. Academy of Management Journal, 50(4): 775-782.

Hardy, C., \& Maguire, S. 2008. Institutional entrepreneurship. In R. Greenwood, C. Oliver, K. Sahlin, \& R. Suddaby (Eds.), The Sage handbook of organizational institutionalism: 198-217. Thousand Oaks, CA: Sage.

Harzing, A. W. K. 2005. Australian research output in economics \& business: High volume, low impact? Australian Journal of Management, 30(2): 183-200.

Harzing, A. W. K. 2008a. Journal quality list. 31 st ed., 31 May 2008, downloaded from www.harzing.com 1 August 2008.

Harzing, A. W. K. 2008b. Publish or Perish, version 2.5.3171, http://www.harzing.com/pop.htm, accessed 15 October 2008.

Harzing, A. W. K., \& van der Wal, R. 2008a. Google Scholar as a new source for citation analysis. Ethics in Science and Environmental Politics, 8(1): 62-71.

Harzing, A. W. K., \& van der Wal, R. 2008b. Comparing the Google Scholor H-index with the ISI Journal Impact Factor, harzing.com white paper, first version, 3 July 2008, http:// www.harzing.com/h_indexjournals.htm.

Inkpen, A. C., \& Beamish, P. W. 1994. An analysis of twenty-five years of research in the Journal of International Business Studies. Journal of International Business Studies, 25(4): 703713.

Johnson, J., \& Podsakoff, P. 1994. Journals of influence in the field of management: An analysis using Salancik's index in a dependency network. Academy of Management Journal, 37(5): 1392-1407.

Kerr, S. 1975. On the folly of rewarding A, while hoping for B. Academy of Management Journal, 18(4): 769-783.

Kirkman, B., \& Law, K. 2005. International management research in AMJ: Our past, present and future. Academy of Management Journal, 48(3): 377-386.

Khurana, R. 2007. From higher aims to hired hands: The social transformation of business schools and the unfulfilled promise of management as a profession. Princeton, NJ: Princeton University Press.

Kumar, V., \& Kundu, S. K. 2004. Ranking the international business schools: Faculty publication as the measure. Management International Review, 44: 213-228. 
Lanchester, J. 2008. Log on. Tune out. Review of Lee Siegel's Against the Machine: Being Human in the Age of the Electronic Mob. New York Times, February 3.

Lawrence, P. A. 2008. Lost in publication: How measurement harms science. Ethics in Science and Environmental Politics, 8, published on-line January 31: 1-3.

Lawrence, P. A. 2003. The politics of publication: Authors, reviewers, and editors must act to protect the quality of research. Nature, 422 (March 20): 259-261.

Lawrence, P. A. 2002. Rank injustice: The misallocation of credit is endemic in science. Nature, 415 (February 21): 835-836.

MacDonald, S., \& Kam, J. 2007. Aardvark et al.: Quality journals and gamesmanship in management studies. Journal of Information Science, 33(6): 702-717.

Macri, J., \& Sinha, D. 2006. Rankings methodology for international comparisons of institutions and individuals: An application to economics in Australia and New Zealand. Journal of Economic Surveys, 20(1): 111-156.

Mangematin, V., \& Baden-Fuller, C. 2008. Global contests in the production of business knowledge: Regional centres and individual business schools. Long Range Planning, 41(1): 117-139.

March, J. G. 1996. Continuity and change in theories of organizational action. Administrative Science Quarterly, 4l(2): 278-287.

Merton, R. K. 1936. The unanticipated consequences of purposive social action. American Sociological Review, 1(6): 894904.

McGahan, A. M. 2007. Academic research that matters to managers: On zebras, dogs, lemmings, hammers, and turnips. Academy of Management Journal, 50(4): 749-753.

McGrath, R. G. 2007. No longer a stepchild: How the management field can come into its own. Academy of Management Journal, 50(6): 1365-1378.

Morgan, H., Harkins, P., \& Goldsmith, M. (Eds.) 2005. The art and practice of leadership coaching: 131-137. NY: John Wiley \& Sons.

Morgeson, F. P., \& Nahrgang, J. D. 2008. Same as it ever was: Recognizing stability in the Business Week Rankings. Academy of Management Learning \& Education, 7: 26-4l.

Morrison, A. J. \& Inkpen, A. C. 1991. An analysis of significant contributions to the international business literature. Journal of International Business Studies, 22(1): 143-153.

Murphy, P. 1996. Determining measures of the quality and impact of journals. Commissioned Report No. 49, Australian Government Publishing Service, Canberra.

Peng, M. W. 2004. Identifying the big question in international business research. Journal of International Business Studies, 35(2): 99-108.

Peng, M. W., \& Zhou, J. Q. 2006. Most cited articles and authors in global strategy research. Journal of International Management, 12(4): 490-508.

Pfeffer, J. 2005. Why do bad management theories persist? A comment on Ghoshal. Academy of Management Learning and Education, 4(1): 96-100.

Pfeffer, J., \& Fong, C. 2002. The end of business schools? Less success than meets the eye. Academy of Management Learning and Education, 1(1): 78-95.

Podsakoff, P. M., MacKenzie, S. M., Bachrach, D. G., \& Podsakoff,
N. P. 2005. The influence of management journals in the 1980s and 1990s. Strategic Management Journal, 26(5): 473488.

Rynes, S. L. 2007a. Academy of Management Journal editor's forum on citations: Editor's forward. Academy of Management Journal, 50(3): 489-490.

Rynes, S. L. 2007b. Academy of Management Journal editor's forum on research with relevance to practice. Editor's foreword: Carrying Sumantra Ghoshal's Torch: Creating More Positive, Relevant, and Ecologically Valid Research. Academy of Management Journal, 50(4): 745-747.

Scott, W. R. 1987. The adolescence of institutional theory. Administrative Science Quarterly, 32: 493-511.

Sauder, M. 2008. Interlopers and field change: The entry of U.S. news into the field of legal education. Administrative Science Quarterly, 53: 209-234.

Sauder, M., \& W. Espeland, W. 2006. Strength in numbers? A comparison of law and business school rankings. Indiana Law Journal, 81: 205-227.

Segalla, M. 2008a. Editorial: Publishing in the right place or publishing the right thing. European Journal of International Management, 2: 122-127.

Segalla, M. 2008b. Publishing in the right place or publishing the right thing: Journal targeting and citations strategies for promotion and tenure committees. Unpublished working paper (expanded version of Segalla 2008a). HEC School of Management, Paris, January 20.

Seligman, M. E. P. 2003. Positive psychology: Fundamental assumptions. Psychologist, 126-127.

Singh, G., Haddad, K. M., \& Chow, C. W. 2007. Are articles in "top" management journals necessarily of higher quality? Journal of Management Inquiry, 16(4): 319-331.

Skopinker, M. 2008. Why business ignores business schools. Financial Times, January 7: 18:18, updated January 8 6:35 at http:// www.ft.com/cms/s/0/215022b8-bd2c-1ldc-b7e6-0000779fd2ac.html.

Spreitzer, G., \& Sonenshein, S. 2003. Positive Deviance and Extraordinary Organizing in Cameron, K. S., Dutton, J. E., \& Quinn, R. E. (Eds.), Positive organizational scholarship: 207224. San Francisco: Berrett-Kohler.

Starbuck, W. H. 2005. How much better are the most-prestigious journals? The statistics of academic publication. Organization Science, 16(2): 180-200.

Starbuck, W. H. 2007. Living in mythical spaces. Organizational Studies, 28(1): 21-25

Swanson, E. 2004. Publishing in the majors: A comparison of accounting, finance, management, and marketing. Contemporary Accounting Research, 21(1): 223-255.

Testa, J. nd. The Thomson Scientific journal selection process. http://www.thomsonreuters.com/business_units/scientific/ free/essays/journalselection/, accessed 15 October 2008.

Tsui, A. S. 2007. From homogenization to pluralism: International research in the academy and beyond. Academy of Management Journal, 50 (6): 1353-1364.

Tung, R. L., \& Witteloostuijn, A. van 2008. What makes a study sufficiently international? Journal of International Business Studies, 39(2): 180-183.

Tushman, M., \& O'Reilly, C. III 2007. Research and relevance: Implications of Pasteur's quadrant for doctoral programs and faculty development. Academy of Management Journal, 50(4): 769-774. 
Van Fleet, D., McWilliams, A., \& Siegel, D. 2000. A theoretical and empirical analysis of journal rankings: The case of formal lists. Journal of Management, 26(5): 839-861.

Vermeulen, F. 2005. On rigor and relevance: Fostering dialectic progress in management research. Academy of Management Journal, 48(6): 978-982.

Vermeulen, F. 2007. I shall not remain insignificant: Adding a second loop to matter more. Academy of Management Journal, 50(4): 754-761.

Werner, S., \& Brouthers, L. E. 2002. How international is management? Journal of International Business Studies, 33(3): 583-591.

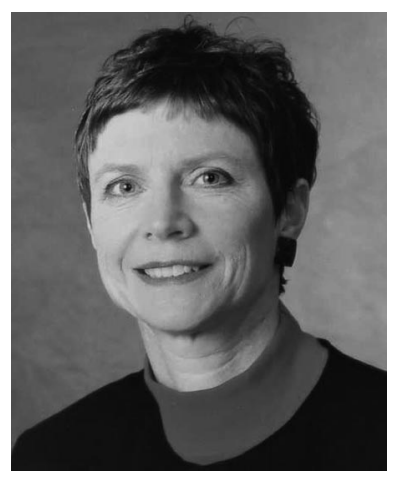

Nancy J. Adler (PhD, UCLA) is the S. Bronfman Chair in Management at McGill University, Montreal, Canada. She conducts research and consults on global leadership and arts and leadership. Dr. Adler is a Fellow of the Academy of Management, the Academy of International Business, and the Royal Society of Canada. Nancy is also a visual artist.
Westney, E. D. 2005. Institutional theory and the multinational corporation. In Sumantra Ghoshal and D. Eleanor Westney (Eds.), Organization theory and the multinational corporation: 47-67. NY: Palgrave MacMillan.

Xu, S., Yalcinkaya, G., \& Seggie, S. H. 2008. Prolific authors and institutions in leading international business journals. Asia Pacific Journal of Management, 25, published on-line November 2007.

Zemsky, R. 2008. The rain man cometh-Again. Academy of Management Perspectives, 22(1): 5-14.

Zucker, L. G. 1987. Institutional theories of organization. Annual Review of Sociology, 13: 443-464.

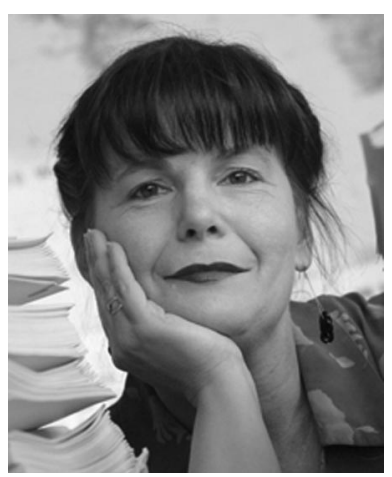

Anne-Wil Harzing ( $\mathrm{PhD}$, University of Bradford) is professor at the University of Melbourne, Australia. Her research interests include international HRM, HQsubsidiary relationships, crosscultural management, and the role of language in international business. Since 1999 she maintains an extensive website (www. harzing.com) with resources for international management and academic publishing. 
Copyright of Academy of Management Learning \& Education is the property of Academy of Management and its content may not be copied or emailed to multiple sites or posted to a listserv without the copyright holder's express written permission. However, users may print, download, or email articles for individual use. 